\title{
Biosorption of Phosphate Ion on Albizia Lebbeck Seed Pod with and Without Organic Acid Modification
}

\author{
ALABI, AH; *OLANREWAJU, CA; SUARA, SO \\ Department of Chemistry, University of Ibadan, Ibadan, Nigeria. \\ *Corresponding Author E-mail Address: olanrewajuclementaji@gmail.com; Tel: +2348067902294
}

\begin{abstract}
This study uses batch experiment to compare the binding efficiency of phosphate onto Albizia lebbeck (ALB) pod with and without citric acid (CALB) or tartaric acid (TALB) modification. The residual phosphate concentration was analyzed using ascorbic acid method and the generated data were fitted into equilibrium isotherms and kinetics models. Intra-particle diffusion model was used to describe the biosorption mechanism. Characterization by FTIR spectroscopy and SEM shows that modification was successful. The maximum biosorption capacity occurred at biosorbent dosage of $0.5 \mathrm{~g}$ for ALB and $1.0 \mathrm{~g}$ for CALB and TALB. At optimum $\mathrm{pH}$ for each biosorbents, phosphate biosorption capacity is in the order ALB>CALB>TALB. Equilibrium time of 90, 150 and 60 minutes were recorded for phosphate on ALB, CALB and TALB respectively. The biosorption capacity increases as the initial anion concentration increases with highest biosorption capacity of $5.296 \mathrm{mg} / \mathrm{g}$ for ALB. Langmuir isotherm describes CALB data while TALB data fits Freundlich. Results from this study suggest that unmodified Albizia lebbeck can be used as a low-cost, highly-efficient biosorbent for phosphate removal in effluents.
\end{abstract}

\section{DOI: https://dx.doi.org/10.4314/jasem.v22i5.7}

Copyright: Copyright $\odot 2018$ Alabi et al. This is an open access article distributed under the Creative Commons Attribution License (CCL), which permits unrestricted use, distribution, and reproduction in any medium, provided the original work is properly cited.

Dates: Received: 09 March 2018; Revised: 06 April: 2018; Accepted: 14 April 2018

Keywords: Biosorption, Phosphate, citric acid, tartaric acid, Albizia lebbeck

Phosphate is an essential nutrient required for plant and microorganism growth whether in aquatic or terrestrial environment, it's excess beyond desired limit in aquatic environment causes eutrophication which results into algae bloom and water quality degradation due to nutrient ratio alteration (Das et al., 2006). Algae bloom at long run depletes dissolved oxygen that results to fish killing and other aquatic animal thus affecting economy through food supply and job opportunity (Yeoman et al., 1988; Karageorgiou et al.,2007). Ingestion of excess phosphate can also cause hyperphosphataemia which is frequently found in patients suffering from chronic or acute renal failure, it leads to calcification of soft tissues and osteodistrophy. This represent a serious side effect of renal failure (Aharoni et al., 1979). Therefore, effluents containing phosphate must meet effluent quality standards of $0.5-1.0 \mathrm{mg} / \mathrm{L} \mathrm{P}$ before its discharge to the receiving water bodies. In order to achieve this objective, phosphate removal from effluents prior to discharge into water bodies is necessary (Urgulu et al., 1998; Bhargava and Sheldarkar 1993; Ozacar, 2003). The major form of phosphate in wastewater is orthophosphate which can originate from point source for example effluents from industrial processes (fertilizer, detergent, metal coating water softening, pigment formulation, food and drinks.(Karageorgiou et al., 2007) and non-point source e.g run off from farms. Municipal wastewater may contain upto $15 \mathrm{mg} / \mathrm{L}$ phosphorus as phosphate while industrial effluents may contain $10 \mathrm{mg} / \mathrm{L}$ in excess(Mezenner and Bensmaili, 2009). Various techniques have been used for phosphate removal, among these chemical precipitation and biological methods have been widely applied (Yeoman et al., 1988). Chemical treatment involves the use of precipitants such as iron salt, lime and alum for treatment (Ugurlu et al., 1998), this result into difficulty of sludge handling, disposal cost and effluent neutralization (Neufeld and Thodos, 1969).

Recently, adsorption have been employed by researchers in removing phosphate from aqueous solution due to the benefit of low cost, high efficiency, adsorbent regeneration, competitiveness, possibility of adsorbate recovery and minimization of chemical and biological sludge. Phosphate adsorption from aqueous solution has been studied by several researchers using different adsorbent like red seaweed (Rathod et al., 2014), carbon residue (Zhang et al., 2013), cacao shell (Hale et al., 2013), sugarcane bagasse fibre (Carvalho et al., 2011), sludge (Song et al., 2011), algae (Yao et al., 2011), wheat straw (Xu et al., 2011), orange waste 
gel (Biswas et al., 2008), peat (Xiong and Mahmood, 2010).

Albizia lebbeck seed pods is an agricultural waste composed of $36.4 \%$ cellulose, $18.9 \%$ hemicelluose, $13.6 \%$ lignin, and $83.1 \%$ volatile matter (Fernandez et al., 1996). The high volatile and lignocellulosic contents in Albizia lebbeck seed pods promote the use of these pods as precursors for production of low cost activated carbon with a well-developed micropores structure (Ahmed and Theydan, 2013). This present study investigate and compare phosphate biosorption capacity on modified and unmodified albizia lebbeck seed pod, this was done as a function of dosage, time, $\mathrm{pH}$ and concentration. The equilibrium and kinetic data are fitted into equilibrium isotherm and kinetic models respectively.

\section{MATERIALS AND METHODS}

Equipment and Reagent: All chemicals/reagents used in this study were of analytical reagent grade, they were used as obtained without further purification. The deionized water used was obtained from International Institute of Tropical Agriculture (IITA, Ibadan). A pHep Hanna (HI 98128 USA, Romania) $\mathrm{pH}$ meter was used for $\mathrm{pH}$ measurements. The $\mathrm{pH}$ meter was calibrated using standard buffer solutions of $\mathrm{pH}$ 4.0, 7.0 and 9.0. The FTIR spectra were recorded using (FTIR System Nicolet IR-200, USA) infrared spectrophotometer between the wave numbers 4000 and $350 \mathrm{~cm}^{-1}$. General Science - UV spectrophotometer (Hongkong) was used to take the absorbance readings. Gallenkamp end-to-end shaker (England) was used to agitate at 120 oscillations/min, Esco Isotherm forced convection laboratory oven (Singapore) was used for all drying purposes and Soehnle professional analytical balance (9401) was employed for all weighing activities.

Biosorbent preparation: The Albizia lebbeck pods were collected from the premises of University of Ibadan, Oyo state, Nigeria, with coordinates $7.4454^{\circ}$ $\mathrm{N}, 3.8986^{\circ} \mathrm{E}$. The pods were hand-picked from around the tree and the seeds were removed from the pods. The adsorbent was prepared according to the method described by Raju et al., 2012. The Albizia lebbeck pods were washed with tap water three times and once with distilled water to remove the adhering dirt (impurities) and it was sun-dried for one week. The dried pods were crushed to powder using a mechanical grinding machine, the grinded pods were then washed with deionized water and dried in the oven at $105^{\circ} \mathrm{C}$. It was then sieved using a $425 \mu \mathrm{m}$ sieve. This was named un-modified Albizia lebbeck and was labeled as ALB. The citric acid and tartaric acid modification follow the procedure of (Marshall et al.,1999; Kumar et al.,
2010). This biomass named ALB was mixed with $0.6 \mathrm{M}$ citric acid (CA) (11.52g of the anhydrous acid in $100 \mathrm{~mL}$ deionized water (Patil et al., 2012) in the ratio of $1.0 \mathrm{~g}$ ALB powder to $7.0 \mathrm{~mL}$ of CA (i.e. $4.2 \mathrm{mmole}$ ), where the ALB powder readily absorbed the acid and this ratio of powder to acid was observed to ensure that the powder had completely absorbed the liquid. The acid/powder slurry was dried overnight at $50^{\circ} \mathrm{C}$. The CA-treated ALB was placed on a WhatmanNo.1filter paper and washed in a Buchner funnel under vacuum with $150-200 \mathrm{~mL}$ of deionized water per gram of the product to remove excess CA. This volume of water was sufficient to remove unreacted CA, since no turbidity from $\mathrm{Pb}$ (II) citrate was observed when the washed powder was suspended in $10 \mathrm{~mL}$ of water, to which $10 \mathrm{~mL}$ of $0.1 \mathrm{M}$ lead (II) nitrate was added. The treated powder was dried at $50^{\circ} \mathrm{C}$ overnight and sieved with $425 \mu \mathrm{m}$ sieve size. It was then labeled CALB. The same procedure was followed for tartaric acid (TA) modification, the powder was washed clean from excess tartaric acid, and this was ensured since there was no formation of potassium tartarate when potassium nitrate was added. The TA- treated ALB was labeled TALB.

Reaction efficiency: The modification reaction efficiency was studied by following the procedure used by (Marshall et al., 2001). In this study, 28.8g of the adsorbent was modified with $250 \mathrm{~mL} 0.6 \mathrm{M}$ citric acid, thus $0.8064 \mathrm{~g}$ is used to modify $1 \mathrm{~g}$ adsorbent. After washing $1 \mathrm{~g}$ adsorbent with $200 \mathrm{~mL}$ deionized water, the filtrate was evaporated, and the recovered citric acid was weighed. This procedure was followed for tartaric acid modification. The percentage reaction efficiency of the modifications was calculated using the relationship below;

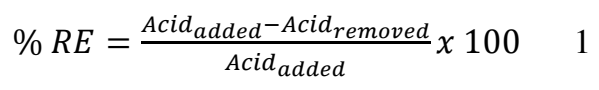

Where $\mathrm{RE}=$ reaction efficiency

Determination of point of zero charge: The Point of Zero Charge (PZC) of the biosorbent was determined following the procedure of Kumar et al., (2010): $100 \mathrm{~mL}$ of double-distilled water was added to an Erlenmeyer flask, capped with cotton and was slowly and continuously heated until boiling for $20 \mathrm{~min}$ to expel the dissolved $\mathrm{CO}_{2}$. The flask was capped immediately to prevent reabsorption of atmospheric $\mathrm{CO}_{2}$ by water. $0.2 \mathrm{~g}$ of the biosorbents (ALB, CALB, and TALB) was placed in another $25 \mathrm{~mL}$ Erlenmeyer flask with $15 \mathrm{~mL}$ of $\mathrm{CO}_{2}$-free water. The flask was sealed with a rubber stopper and left in continuous agitation for $48 \mathrm{~h}$ at room temperature and then filtered. 
Then the $\mathrm{pH}$ of the filtrate was measured, and this value has been taken as the point of zero charge.

Preparation of phosphate solution: Standard stock solution of $1000 \mathrm{mg} / \mathrm{L}$ of phosphate was prepared by dissolving $1.4316 \mathrm{~g}$ of potassium dihydrogen phosphate in deionized water and then quantitatively made up to mark with deionized water in a $1 \mathrm{~L}$ standard flask. Working standards of desired concentration were then subsequently prepared from the stock solution. The calibration curve of phosphate for UVvisible analysis (ascorbic acid method) was prepared by diluting the stock solutions to various concentrations range (4 - 20mg/L, step size: $4 \mathrm{mg} / \mathrm{L})$. Reagent blank was used as reference solution. Phosphate concentration was read at $880 \mathrm{~nm}$. (APHA, 1998).

Batch Equilibrium Experiment: All experiments were carried out in duplicates for the biosorbent and the mean value of the duplicate result was determined and used. Blank batch study was also carried out to correct for turbidity and interfering color. The effect of dosage was carried out by mixing varying amount of the biosorbent $(0.1,0.2,0.4,0.5,0.8,1.0,1.2 \mathrm{~g})$ in series of sample bottles with $50 \mathrm{~mL}$ of the adsorbate solution (50mg/L phosphate) each. The sample bottles were shaken on an end-to-end shaker for 3hours. The $\mathrm{pH}$ effect was studied using the initial anion concentration of $2.5 \mathrm{mg}$ in $50 \mathrm{~mL}$ of deionized water, the weight as used in effect of time consideration were used and the bottles were shaken for each biosorbent equilibrium time. The studies were carried out at a $\mathrm{pH}$ range $(2-$ 10, step size: 1 ), adjustment was done using $0.1 \mathrm{M}$ $\mathrm{NaOH}$ and $0.1 \mathrm{M} \mathrm{HCl}$. To study effect of initial concentration, equilibrium dosage for each biosorbent was mixed with $50 \mathrm{~mL}$ of different $\mathrm{PO}_{4}^{-3}$ concentration. The solutions were shaken on an endto-end shaker at equilibrium time and the study was carried out at an optimum $\mathrm{pH}$ with respect to the biosorbent per time. At the end of each shaking, the solutions were filtered using a Whatman No. 1 Filter Paper and the filtrate of each solution analyzed for residual anion concentration using General Science UV spectrophotometer (Hongkong) at 880nm. The amount of phosphate biosorbed at equilibrium $\mathrm{q}_{\mathrm{e}}$ (mg/g), was obtained using this equation.

$$
q e=(C o-C e) V / M
$$

Where $C_{0}$ and $C_{e}$ were initial and equilibrium concentrations of phosphate $(\mathrm{mg} / \mathrm{L})$, respectively, $m$ was the mass of adsorbent ( $\mathrm{g}$ ) and $V$ was volume of the solution (L). The removal efficiency was calculated using the following equation:

$$
\% \text { Removal }=\left(\frac{C_{o}-C_{e}}{C_{o}}\right) \times 100 \quad 3
$$

Batch Kinetics experiment: The effect of contact time on phosphate removal was carried out using equilibrium dosage of each biosorbents. The equilibrium dosage obtained from dosage batch study were mixed with $50 \mathrm{mg} / \mathrm{L} \mathrm{PO}_{4}^{-3}$ in solution $(2.50 \mathrm{mg}$ in $50 \mathrm{~mL}$ deionized water). The sample bottles were labeled for time intervals 15, 30, 60, 90, 120, 150, and 180 minutes. The sample bottles were tightly covered and shaken at the appropriate time interval using an end-to-end shaker (Adediran et al., 2007). At the end of each time interval, the suspension was filtered using Whatman No. 1 filter paper and analyzed. The amount

of adsorbed phosphate at time $t, q_{t}(\mathrm{mg} / \mathrm{g})$, was calculated by:

$q_{t}=\left(\frac{C_{o}-C_{t}}{M}\right) \times V$

Where $C_{t}(\mathrm{mg} / \mathrm{L})$ is the $\mathrm{PO}_{4}^{-3}$ concentration at time $t$.

Isotherm models: The most appropriate approach for assessing biosorbent capacity of any biosorbent is through sorption isotherms, they describe how biosorption molecules distribute between the liquid phase and the solid phase when the biosorption reaches state of equilibrium. Biosorption can be characterized by a variety of equilibrium isotherm models. In this present study, biosorption data were fitted into three sorption models, the parameters obtained from the models provide important information about the biosorbent affinity for phosphate, its surface property and the sorption mechanism.

The Langmuir isotherm assumes adsorption takes place at specific homogeneous sites within the adsorbent, adsorption is limited to monolayer coverage, the ability of a molecule to be adsorbed on a given site is independent of its neighbouring sites occupancy, equivalent sorption energies and all surface sites are alike and only can accommodate one adsorbed atom (Langmuir, 1916). By applying these assumptions, a kinetic principle (rate of adsorption and desorption from the surface is equal). Langmuir isotherm can be linearized in four different types of equations and simple linear regression will result in different parameter estimates (El-sikaily et al., 2007). The Langmuir equation may be written as: 


$$
q_{e}=\frac{Q_{m} K_{L} C_{e}}{1+K_{L} C_{e}} \quad 5
$$

The above equation can be rearranged to the following four linearized equation

$\begin{array}{lll}\text { Langmuir 1 } & \frac{C_{e}}{q_{e}}=\frac{1}{K_{L} Q_{m}}+\frac{1}{Q_{m}} C_{e} & 6 \\ \text { Langmuir 2 } & \frac{1}{q_{e}}=\frac{1}{K_{L} Q_{m}}+\frac{1}{C_{e} Q_{m}} & 7\end{array}$

Langmuir $3 \quad q_{e}=Q_{m}-\frac{1}{K_{L} C_{e}} q_{e} \quad 8$

Langmuir $4 \frac{q_{e}}{C_{e}}=K_{L} Q_{m}-K_{L} q_{e}$

along time to reach equilibrium. The kinetic data the amount of adsorbate ion sorbed $(\mathrm{mg} / \mathrm{g})$; $\mathrm{Q}_{\mathrm{m}}$ the $\mathrm{q}_{\mathrm{e}}$ for a complete monolayer $(\mathrm{mg} / \mathrm{g}) ; \mathrm{K}_{\mathrm{L}}$ is the sorption equilibrium constant $(\mathrm{L} / \mathrm{mg})$. A plot of $\mathrm{C}_{\mathrm{e}} / \mathrm{q}_{\mathrm{e}}$ versus $\mathrm{C}_{\mathrm{e}}$ (Langmuir-1), $1 / \mathrm{q}_{\mathrm{e}}$ versus $1 / \mathrm{C}_{\mathrm{e}}$ (Langmuir-2), $\mathrm{q}_{\mathrm{e}}$ versus $\mathrm{q}_{\mathrm{e}} / \mathrm{C}_{\mathrm{e}}$ (Langmuir-3) and $\mathrm{q}_{\mathrm{e}} / \mathrm{C}_{\mathrm{e}}$ versus $\mathrm{q}_{\mathrm{e}}$ (Langmuir-4) should indicate straight lines.

The Freundlich isotherm is an empirical equation based on an exponential distribution of adsorption sites and energies. It can describe the adsorption of organic and inorganic compounds on a wide variety of adsorbents including biosorbents. The Freundlich equation may be written as:

$$
q_{e}=k_{F} C_{e}^{\frac{1}{n}}
$$

The equation is conveniently used in the linear form by taking the logarithm of both sides as:

$\log q_{e}=\log K_{F}+\frac{1}{n} \log C_{e}$

The constants $\mathrm{K}_{\mathrm{F}}$ and $\frac{1}{n}$ of the Freundlich model are the constants indicative of the relative adsorption capacity of the adsorbent $(\mathrm{mg} / \mathrm{g})$ and the constant indicative of the intensity of the adsorption, respectively (Freundlich, 1906).

The Temkin isotherm is based on the assumption that the heat of adsorption would decrease linearly with the increase of coverage of adsorbent. The isotherm was developed by Temkin and Pyzhev 1940 and it is given by the following expression:

$$
\frac{Q_{e}}{b_{t}}=R T \ln \left(\alpha_{t} C_{e}\right)
$$
obtained from batch studies can be analyzed using the pseudo-first order, pseudo-second order, Elovich model and Intra-particle diffusion model (Han et al., 2007). Pseudo-first order equation of Lagergren may have been the first rate equation for the sorption in liquid/solid systems based on solid capacity it is expressed as

$$
\frac{d q}{d t}=K_{1}\left(q_{e}-q\right)
$$

Where $\mathrm{R}$ is the gas constant, $(\mathrm{J} / \mathrm{mol} / \mathrm{K}), \mathrm{T}$ is the heat of adsorption and $\alpha_{t}$ is the Temkin isotherm constant.

Kinetics Model: The rate of the adsorption process and potential rate-controlling step are best explained using kinetics models i.e. it describes reaction pathway expressed as

Where $\mathrm{q}_{\mathrm{e}}$ and $\mathrm{q}$ are the amount adsorbed at equilibrium and at time $(\mathrm{min})$ respectively, and $K_{1}$ is the rate constant of pseudo-first order sorption $\left(\mathrm{min}^{-1}\right)$.

The integrated form of Equation

$$
\ln \left(q_{e}-q\right)=\ln q_{e}-K_{1} t \quad 14
$$

A plot of $\ln \left(q_{e}-q\right)$ against $t$ should give a linear relationship with the slope $\mathrm{K}_{1}$ and intercept of $\ln \mathrm{q}_{\mathrm{e}}$.

The pseudo-second order kinetic rate equation may be expressed as follows:

$$
\frac{d q t}{d t}=K_{2}\left(q_{e}-q\right)^{2} \quad 15
$$

Where $k_{2}$ is the rate constant of pseudo-second order sorption (mg/g min), $\mathrm{q}_{\mathrm{e}}$ and $\mathrm{q}$ are the amount adsorbed at equilibrium and at time $t$ respectively.

The integrated form of equation (16) becomes:

$$
\frac{t}{q}=\frac{1}{k_{2} q_{e}^{2}}+\frac{1}{q_{e}} \cdot t
$$

A plot of $t / q$ against $t$ should give a linear relationship. The $\mathrm{q}_{\mathrm{e}}$ and $\mathrm{k}_{2}$ can be determined from the slope and intercept of the plot (Uddin et al., 2007). The Elovich equation is generally expressed as;

$$
\frac{d_{q}}{d_{t}}=\alpha \exp ^{(-\beta q t)}
$$

Where $\mathrm{q}$ is the amount adsorbed at time $\mathrm{t}, \alpha$ and $\beta$ are constants during any one experiment. The constant $\alpha$ can be regarded as initial rate since $\mathrm{dq} / \mathrm{dt} \rightarrow \alpha$ as $\mathrm{q} \rightarrow$ 0 , i.e., a rapid adsorption not governed by the exponential law (Low, 1960). Assuming that $\mathrm{q}=0$ at $\mathrm{t}$ $=0$, the integrated form of Equation (17) becomes 


$$
q=\left(\frac{1}{\beta}\right) \ln (1+\alpha \beta t)
$$

To simplify the Elovich equation, we assume $\alpha \beta \mathrm{t}>>1$, Equation (18) thus can be simplified as

$$
q=\left(\frac{1}{\beta}\right) \ln (\alpha \beta)+\left(\frac{1}{\beta}\right) \ln t \quad 19
$$

Thus, a plot of $\mathrm{q}$ vs. $\ln \mathrm{t}$ should give a linear relationship with the slope of $(1 / \beta)$ and intercept of $(1 / \beta) \ln (\alpha \beta)$. (Chien and Clayton, 1955)

According to Weber and Morris, kinetic model should identify if the sorption process is intra-particle diffusion mechanism or not. It has been shown to be an important factor in determining the attainment of equilibrium in immobilized biosorbent.

The intra-particle diffusion model equation is given as

$$
q_{t}=k_{i d} t^{1 / 2}+c
$$

The $k_{i d}$ values can be calculated from the slope of the plot of $\mathrm{q}_{\mathrm{t}}$ against $\mathrm{t}^{1 / 2}$ which gives a multi-linear form for biosorption of adsorbate. The initial portion of curve is reflecting the boundary layer diffusion effect and final linear part of curve show the effect of intraparticle diffusion. The larger the intercept, the greater the contribution of the surface sorption in the rate controlling step i.e. the value of $c$ gives an idea about the thickness of boundary layer. If the plot passes through the origin, then intra-particle diffusion is the rate-determining step (Park et al., 2010).

\section{RESULT AND DISCUSSION}

Characterization of Biosorbent: The characterization became necessary since adsorption is a surface phenomenon and to know the extent of modification done by the modifying acids. Reaction efficiency and point of zero charge was also determined. Reaction efficiency between the biosorbents and the two modifying acids were estimated to be $56 \%$ for Citric acid modification and $34 \%$ for Tartaric acid modification. The morphological structures of ALB, CALB and TALB were provided by SEM studies (Fig1). The surface morphology of ALB is different from that of CALB and TALB, which might exhibit microstructure porosity for untreated biomass and acid -treated biomass. The surface morphology ALB powder showed that the powder was an assemblage of fine flakes with pores which did not have regular, fixed shape and size. The particles were of various dimensions and all of them contained many steps and kinks on the external surface, with broken edges. The surface morphologies of the ALB were an assemblage of rough and fibrous porous flakes, this occurred due to the intrinsic nature of biomass (Figla). Fig1b and 1c shows that the citric and tartaric acid used for modification effect a change in surface morphology of CALB and TALB when compared to surface morphology of ALB as shown in Figla. The citric acids restructured the biomass into a neat homogeneous flattened flake. Likewise, tartaric acid restructured it in such a way that makes occlusion of phosphates ions possible. The size of the voids in the CALB was decreased after citric acid treatment and some distortion of the shape could be seen in the SEM of CALB and TALB. TALB exhibits pores like honeycomb shape gaps after modification.
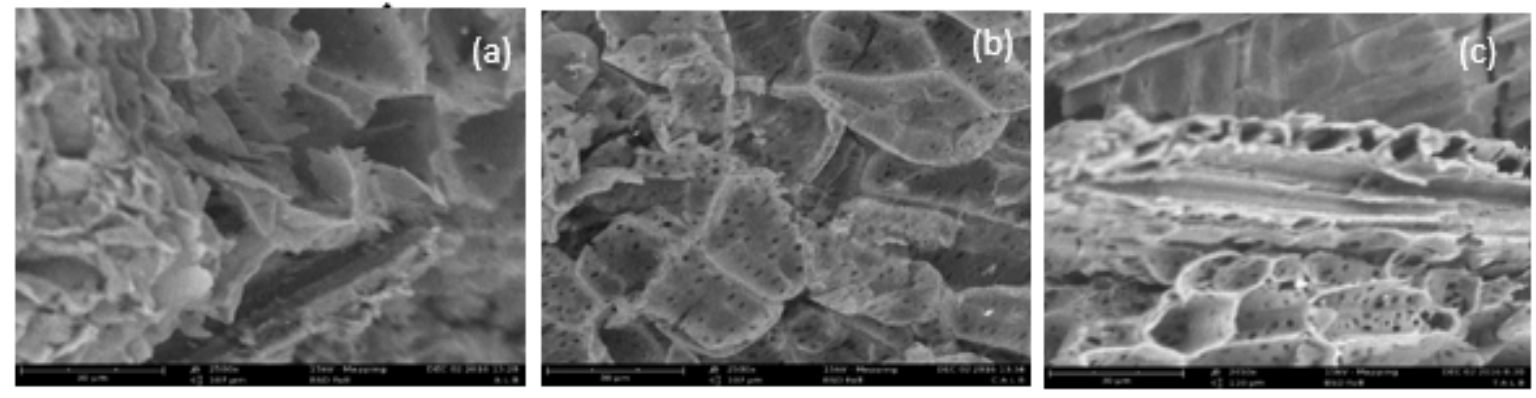

Fig 1: Scanning Electron Microscopy of (a) ALB (b) CALB (c) TALB 


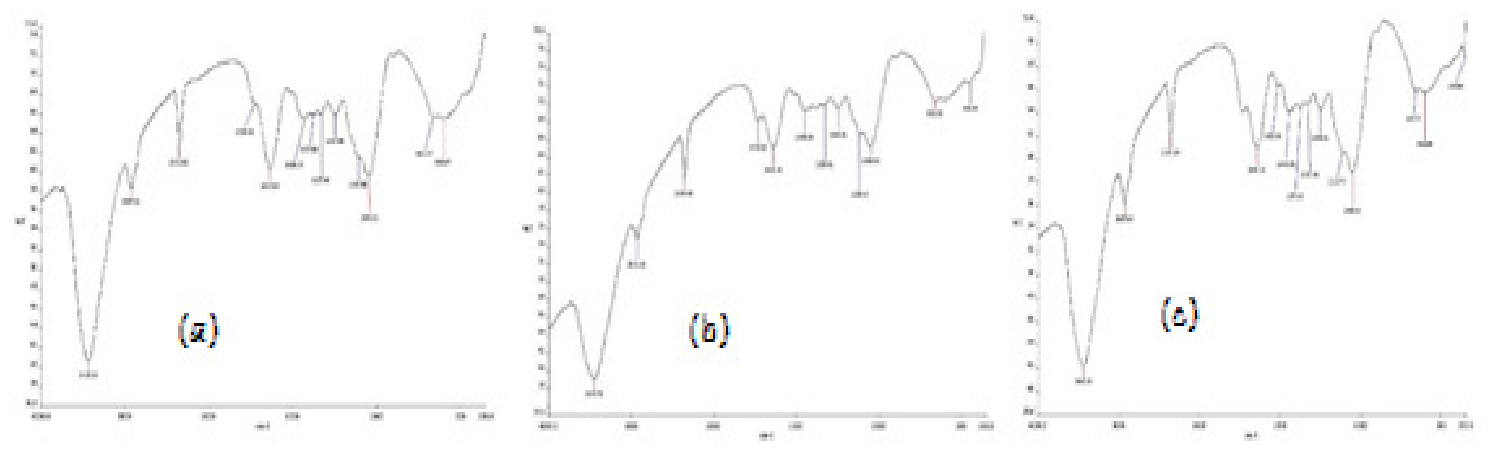

Fig 2: Fourier Transformed Infrared Spectroscopy of (a) ALB (b) CALB (c) TALB

The corresponding Fourier Transform Infrared (FTIR) spectra of the biosorbent recorded on a Perkin-Elmer Spectrum version 10.4.3 spectrometer over the range of $4000-350 \mathrm{~cm}^{-1}$ before modification and after the modification with citric and tartaric acids are shown in Figure 2. The FTIR characterization drawn from the analysis of the main functional groups is useful in explaining the biosorption behavior of ALB, CALB and TALB. The broad and intense peak on ALB at $3439.00 \mathrm{~cm}^{-1}, 3451.78 \mathrm{~cm}^{-1}$ for CALB and 3440.00 $\mathrm{cm}^{-1}$ for TALB (from the range of $3200-3600 \mathrm{~cm}-1$, in Figure 2), was assigned to be $\mathrm{OH}$ group stretching due to hydrogen bonding inter-molecular and intramolecular polymer by compounds such as alcohols, phenols and carboxylic acid.

Sharp peaks at $2927.16,2931.56$ and $2927.63 \mathrm{~cm}^{-1}$ on ALB, CALB and TALB respectively correspond to C - $\mathrm{H}$ stretching vibration frequencies. The medium peak at 2352.92, 2354.56 and $2354.39 \mathrm{~cm}^{-1}$ on ALB, CALB and TALB is the spectrum of the $\mathrm{OH}$ group attributed to strong hydrogen bonding present, thus indicating the presence of carboxylic acid in the biosorbent. Peaks at 1635.85 on ALB, 1639.30 on CALB and $1642.10 \mathrm{~cm}^{-1}$ on TALB, were assigned to $\mathrm{C}=\mathrm{O}$ amide stretching vibrations or $\mathrm{C}=\mathrm{C}$ groups. The sharp peaks at $1046.61 \mathrm{~cm}^{-1}$ on ALB, $1049.00 \mathrm{~cm}^{-1}$ on CALB and $1050.42 \mathrm{~cm}^{-1}$ on TALB correspond to the $\mathrm{S}=\mathrm{O}$ sulfoxide $\left(1050 \mathrm{~cm}^{-1}\right)$ stretching vibrations, meanwhile, several bands were indicated on ALB $\left(1327.46 \mathrm{~cm}^{-1}\right)$, CALB $\left(1375.90 \mathrm{~cm}^{-1}\right)$ and TALB $\left(1327.46 \mathrm{~cm}^{-1}\right)$ in the region $1375-1300 \mathrm{~cm}^{-1}$ and 1350 $-1140 \mathrm{~cm}^{-1}$ stretching vibration corresponding to $\mathrm{S}=\mathrm{O}$ sulphones, sulphonyl chloride, sulphates and sulphonamides, this peaks showed that the functional group $\mathrm{S}=\mathrm{O}$ is higher in ALB compared to other biosorbent. Peaks at $600.47 \mathrm{~cm}^{-1}$ on ALB, 661.00 on CALB and 602.26 correspond to $\mathrm{C}-\mathrm{H}$ bending vibrations. These peaks showed the dominant functional groups involved in phosphate biosorption.
Higher absorption bands of CALB and TALB observed in the spectrum is an indication of the successful modification of the biosorbent. The SEM analysis further confirmed the result obtained by the FTIR studies that the modification carried out on the biomass albizia lebbeck seed pod, using citric acid and tartaric was successful.

Effect of Biosorbent dosage: The effect of biomass dosage on phosphate removal was carried out between 0.1 and $1.2 \mathrm{~g}$ with phosphate initial concentration of $50 \mathrm{ppm}$ at $180 \mathrm{~min}$ contact time for all biosorbent. As it is seen from Fig 3, the increase in biosorbent dosage from $0.1 \mathrm{~g}$ to $0.4 \mathrm{~g}$ resulted in percentage increase of phosphate removal from $27.67-55.16 \%$, this can be justified by the relative increase of new binding sites. Although a lower increment of anion removal was observed above $0.4 \mathrm{~g} / \mathrm{L}$, this lower increment results in decreasing of equilibrium uptake capacity. Furthermore, equilibrium uptake capacity was decreased from 43.45 to $7.75 \mathrm{mg} / \mathrm{g}$ with increasing biomass concentration from 0.4 to $1.2 \mathrm{~g} / \mathrm{L}$ this is possibly due to the strong inhibition of phosphate species mobility in the biosorption medium, thus leaving some binding sites unsaturated. This observation was reported by Aryal, 2011.

Therefore, an equilibrium dosage of $0.5 \mathrm{~g}$ was selected for ALB in further studies. For CALB, percentage removal increases as the dosage increases from $0.1 \mathrm{~g}$ to $0.4 \mathrm{~g}$, this occur because of increase of binding site. A lower biosorption was observed at $0.5 \mathrm{~g}$ and increases again as the biosorbent dosage rises to $1.0 \mathrm{~g}$. Highest biosorption was recorded at $1.0 \mathrm{~g}$. For TALB, percentage removal increases from $0.011 \%-14.10 \%$ as the biosorbent dosage increases from $0.1 \mathrm{~g}-0.5 \mathrm{~g}$.

This can also be explained by increase of binding sites; high percentage removal was attained at $1.0 \mathrm{~g}$ biosorbent dosage. Therefore, optimum value of $1.0 \mathrm{~g}$ were chosen for both CALB and TALB as biosorbent dosage in further studies. 


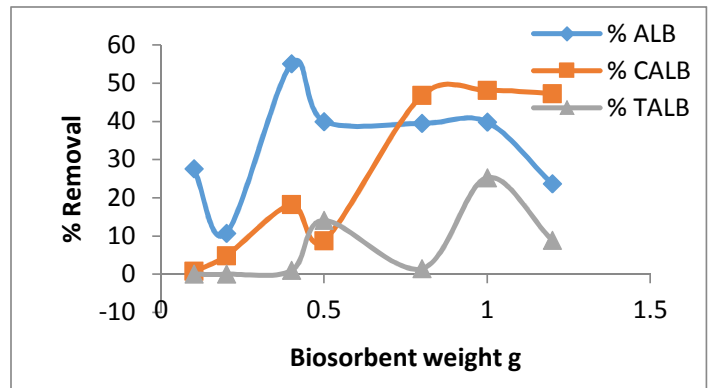

Fig 3: Effect of biosorbent weight on the biosorption of $\mathrm{PO}_{4}{ }^{3-}$ on Albizia lebbeck (ALB, CALB and TALB) pods powder.

Effect of $p H$ : Phosphates exist as neutral $\mathrm{H}_{3} \mathrm{PO}_{4}$ species at $\mathrm{pH}$ lower than 2.0 and, $\mathrm{H}_{2} \mathrm{PO}_{4}{ }^{-}$and $\mathrm{HPO}_{4}{ }^{2-}$ species at $\mathrm{pH}$ between 2.0 and 9.0, whereas $\mathrm{H}_{2} \mathrm{PO}_{4}{ }^{-}$is the major species in aqueous solution at $\mathrm{pH}$ range of 2.0-3.5 (Aryal, 2011). For each $0.4 \mathrm{~g}$ of ALB, $50 \mathrm{~mL}$ of $50 \mathrm{mg} / \mathrm{L}$ was agitated for $90 \mathrm{~min}$ at varied $\mathrm{pH}$ from 210, (step size: 1 ). The $\mathrm{pH}$ of point of zero charge pHpzc is defined as the $\mathrm{pH}$ at which surface charge density $(\sigma 0)$ is zero. The values of pHpzc for ALB, CALB and TALB were found to be 6.5, 5.4 and 4.9 respectively. It was observed that pHpzc increases after modification, this is due to impact of carboxylic group in the organic acid used. The carboxylic group partially dissociates $\mathrm{H}^{+}$into the solution; this indicates that the surface becomes more positively charged and this should probably facilitate the electrostatic interaction with anions ( Anirudhan, 2006). It was observed that highest biosorption of phosphate $(79.23 \%)$ occur at $\mathrm{pH} 2$ for ALB and as the $\mathrm{pH}$ increases, the biosorption capacity of the biosorbent reduces and got to the lowest at $\mathrm{pH} 6$, similar result was reported by Rodriques et al., 2010. This behavior can be explained by electrostatic interaction between the dominant $\mathrm{H}_{2} \mathrm{PO}_{4}^{-}$species in the aqueous solution and the carboxylic group on the biosorbent. More so, there is a possibility of impacting a negative or a positive charge on the functional groups on an adsorbent through $\mathrm{pH}$ control. It is widely believed that anions should adsorb better at $\mathrm{pHs}$ lower than the pHpzc when the functional groups on the adsorbent surface would have taken a positive net charge form. The decrease in biosorption capacity as the $\mathrm{pH}$ increases is due to increase in $\mathrm{HPO}_{4}{ }^{2-}$ species in the solution after which biosorption capacity rises again at $\mathrm{pH} 8$ and then decreases at higher $\mathrm{pH}$. Low adsorption at higher $\mathrm{pH}$ is due to competition for biosorption sites by the anions and $\mathrm{OH}^{-}$Adsorption increases slightly at neutral $\mathrm{pH}$ when hydroxyl ion concentration was still low. This was also reported by (Li et al., 2013). For each $1 \mathrm{~g}$ of CALB agitated with $50 \mathrm{~mL}$ of $50 \mathrm{ppm}$ $\mathrm{PO}_{4}{ }^{3-}$ for $150 \mathrm{~min}$ at varied $\mathrm{pH}$ in the range 2-10, (step size: 1) It was observed that highest adsorption of
$46.29 \%$ occur at $\mathrm{pH} 2$. This is envisaged and justifiable being that at this $\mathrm{pH}$, there is high concentration of $\mathrm{H}^{+}$ impacted by $0.1 \mathrm{M} \mathrm{HCl}$ used for $\mathrm{pH}$ adjustment, the $\mathrm{pH}$ is below pHpzc and the citric acid used in modification is also a tricarboxylic acid, thereby enhancing the solution acidic strength. This made it readily reacts with the anions, this was also observed by (Aryal, 2011). As the $\mathrm{H}^{+}$decreases, the acidic strength decreases, thus decrease in biosorption capacity. At $\mathrm{pHs}$ above pHpzc, anions adsorption decreases due to competition for binding site between phosphate and hydroxyl ion. At about $\mathrm{pH} 5-8$, there is no significant change in \% removal, this is because strong interactions exist between the CALB and phosphate in solution, thus $\mathrm{H}^{+}$and $\mathrm{OH}^{-}$could not affect its $\%$ removal and biosorption capacity.

Phosphate biosorption by TALB was profoundly affected as a function of $\mathrm{pH}$. The amount of Phosphates biosorbed on TALB was the greatest at $\mathrm{pH}$ 6.0 and decreased with either decreasing or increasing $\mathrm{pH}$ (Figure 4.3). Similar result was also recorded by Rathod et al., 2014; Xiong and Mahmood, 2010) This infer that $\mathrm{H}^{+}$concentration does not increase adsorption capacity of the biosorbent and tartaric acid being a weak dicarboxylic acid shows little acidic strength, at higher $\mathrm{pH}$, it was observed that adsorption capacity decreases.

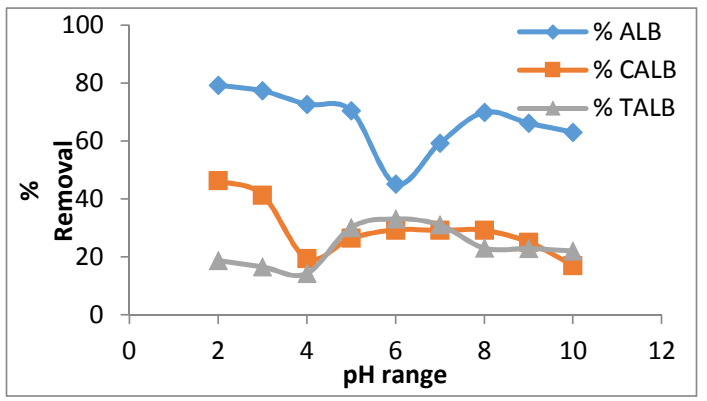

Fig 4: Effect of $\mathrm{pH}$ on the biosorption of $\mathrm{PO}_{4}{ }^{3-}$ on Albizia lebbeck (ALB, CALB and TALB) pods powder.

This was due to competition of biosorption site by $\mathrm{OH}^{-}$ and the anion. This was also observed by (Aryal, 2011; Biswas et al., 2008). On the other hand, higher $\mathrm{pH}$ causes deprotonation of oxide/hydroxides surface and dissociation of functional groups $(-\mathrm{COOH},-\mathrm{OH}$, etc.) of organic matter and subsequently renders the TALB to carry more negative charges, which repel phosphates from the surfaces, thus decreasing its biosorption (Xiong and Mahmood, 2010). The high biosorption capacity for the three biosorbents were all in acidic medium, this observation was also reported by (Biswas et al., 2008; Li et al., 2013; Rhoton and Bigham, 2005) this is so due to concentration of $\mathrm{H}^{+}$in 
the solution and their affinity for the $\mathrm{H}_{2} \mathrm{PO}_{4}^{-}$and $\mathrm{HPO}_{4}{ }^{2-}$ in the solution. Likewise, lower biosorption was noticed at higher $\mathrm{pH}$, this is due to the competition between the anions and the $\mathrm{OH}^{-}$for the available binding site.

\section{Equilibrium Isotherm}

The variation of anion concentration and their percentage removal is illustrated in Fig 5. The biosorption capacity increases with increase in $\mathrm{PO}_{4}{ }^{3-}$ ion concentration for all the three biosorbent (ALB, CALB and TALB). Although ALB show a temporal decrease in $\%$ removal as the concentration increases from $50-80 \mathrm{mg} / \mathrm{L}$ of phosphate ion, but further increase of anion concentration results in increase in \%removal.

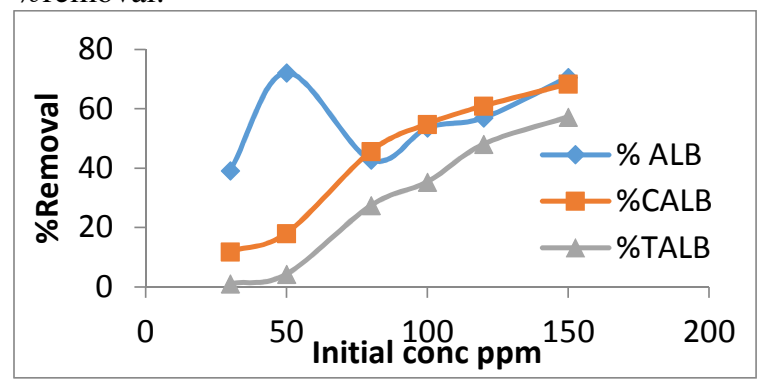

Fig 5: Effect of Initial concentration on the biosorption of $\mathrm{PO}_{4}{ }^{3-}$ on Albizia lebbeck (ALB, CALB and TALB) pods powder.

Langmuir Isotherm: Langmuir Isotherm corresponds to monolayer coverage of the biosorbent surface without the lateral interaction. Table 1 shows Langmuir isotherm parameters for the three adsorbents as used to adsorbed phosphate. For anion adsorption on un-modified Albizia Lebbeck (ALB), the regression value $\mathrm{R}^{2}$ of 0.287 indicates an unsatisfactory description of phosphate biosorption by Langmuir isotherm. The dimensionless constant separation factor, $\mathrm{R}_{\mathrm{L}}$ values for $\mathrm{PO}_{4}{ }^{3-}$ on ALB $(0.752$ $0.378)$ fall within range of $0-1(0<R L<1)$, this depicts a favourable biosorption process. This was also reported by (Li et al., 2013). Likewise, a plot of phosphate on Citric Acid modified Albizia Lebbeck (CALB) and Tartaric Acid modified Albizia Lebbeck (TALB) gave correlation values of 0.958 and 0.977 respectively. This value indicates that the biosorption of phosphates on this adsorbent is satisfactory as shown by the closeness of $\mathrm{R}^{2}$ to unity, this result agrees with the one obtained by (Rodrigues et al., 2010; Xiong and Mahmood, 2010). Moreover, the $\mathrm{R}_{\mathrm{L}}$ values [ $(2.552-(-0.490)$ for CALB and $(1.951-(-$ 0.696) for TALB] indicates a non-favourable biosorption process. The biosorption capacities, qo were found to be $6.85 \mathrm{mg} / \mathrm{g},-0.152 \mathrm{mg} / \mathrm{g}$ and $0.0184 \mathrm{mg} / \mathrm{g}$ for the biosorption of phosphate on ALB, CALB and TALB respectively.
Freundlich Isotherm: The Freundlich isotherm is empirically derived and is described based on two factors namely, the energetic surface heterogeneity and lateral interaction between the adsorbed molecules. These two factors are commonly observed with precipitation process. (Eberhardt et al., 2006). The data obtained from phosphate biosorption on the three biosorbents were fitted into Freundlich isotherm; Table 1 gives a summary of Freundlich constants values and the regression values. Regression values of $0.422,0.802$, and 0.919 were obtained for ALB, CALB and TALB respectively. Equilibrium data of TALB fits better into the Freundlich isotherm as indicated by high $\mathrm{R}^{2}$ value compared to ALB and CALB. Eberhardt et al., 2006 reported similar results in his study of phosphate removal by refined aspen wood. Constant $\mathbf{n}$ in Table 2 is a measure of deviation from linearity, when $\mathrm{n}$ is greater than 1, biosorption bond becomes weak and the value of sorption capacity changes significantly with small changes in concentration (Akbal, 2005). Thus, $\mathrm{n}$ value for phosphate biosorption on ALB is 1.155. When $\mathrm{n}$ value is less than 1, increased biosorption modifies the sorbent in a manner that increases the sorption capacity, such as forming new sites (Santana et al., 2011). Phosphate biosorption on CALB and TALB gave $n$ values of 0.188 and 0.145 respectively.

Temkin Isotherm: The data obtained were also fitted into Temkin Isotherm and results obtained are represented in Table 1 , heat of biosorption $b_{T}$ for phosphate adsorption on the three adsorbent were found to be $1.445,0.395$ and $0.637 \mathrm{KJ} / \mathrm{mol}$ for ALB, CALB and TALB respectively. A plot of Qe $\mathrm{mg} / \mathrm{g}$ against $\mathrm{Ce} \mathrm{mg} / \mathrm{L}$ gives the biosorption isotherm (Fig 6)

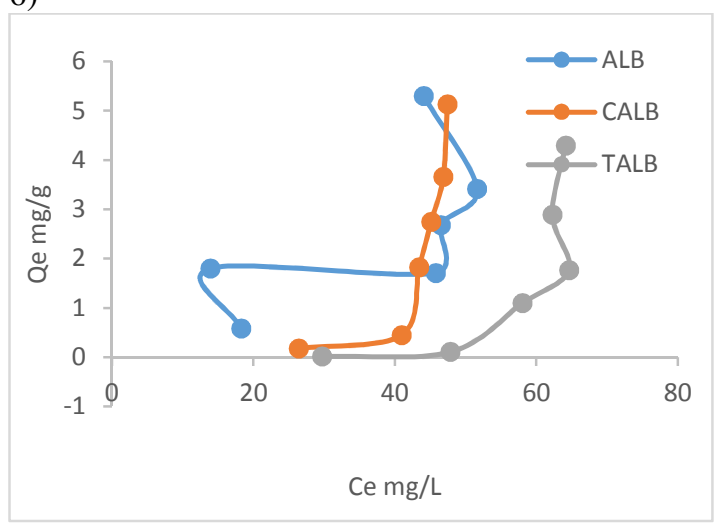

Fig 6: Biosorption Isotherm of $\mathrm{PO}_{4}{ }^{3-}$ on ALB, CALB and TALB at different equilibrium condition

Kinetic Studies: The effectiveness of the three biosorbent can be evaluated with respect to time by the plots of the amount of phosphate biosorbed at a time $\mathrm{q}_{\mathrm{t}}$, as a function of the time (Fig 7). At initial 
biosorption stage, phosphate was rapidly biosorbed by the three biosorbent, this occur due to the biosorption of the molecule on the external surface of the particle. As reported by Rathod et al., (2014), sorption of phosphate anion entails a sluggish and rapid reaction process. In rapid process, biosorption increase in early minutes of the anion contact with the biosorbent. Conversely in sluggish process, biosorption of anion may prolong over hours which may cause decrease in biosorption. Originally, superficial sorption and availability of large binding sites are two major factors that account for rapid sorption of phosphate at the inception of the biosorption process, relative sluggish process sets in when anions enter pores of the biosorbent materials. At this stage, binding sites become saturated and equilibrium attained. Before the attainment of equilibrium, albizia lebbeck modified with citric acid CALB exhibits biosorption and desorption behavior, high amount of the anion was recorded at $150 \mathrm{~min}$. At a time, higher than $150 \mathrm{~min}$, desorption of phosphate molecule occurred. At the beginning of the biosorption process, phosphate ion biosorbed rapidly on TALB and close to half of the phosphate was removed in the first $15 \mathrm{~min}$ of its contact with the biosorbent and at $60 \mathrm{~min}$, equilibrium was attained after which desorption sets in (Fig 7). Similar observation was reported by Aryal, (2011). The results show that sorption process which is faster at the initial stage may be due to the occupation of high affinity binding sites, whereas the slow sorption kinetics observed after that time may reflect the relative inaccessibility of the remaining binding sites. The rapid biosorption of phosphate on ALB at an early stage can be attributed to large number of binding site and their affinity for the molecule. Initially, more than $80 \%$ of phosphate was removed by ALB and equilibrium time of 90min was recorded after which desorption sets in. Higher phosphate removal was observed after the order CALB $>$ ALB $>$ TALB at different equilibrium time. Kinetics models are used to examine the rate of the biosorption process and the potential rate controlling step. In this present study, the kinetics data obtained from batch studies was analyzed using Pseudo-first order, Pseudo-second order and Elovich models. The plots of the model are illustrated in Fig 8. The models predicted values are expressed by the regression equation, $\mathrm{R}^{2}$ and a high value indicates that the model successfully describes the biosorption process.

The pseudo-first order plot of $\log _{10}(\mathrm{qe}-\mathrm{qt})$ against $\mathrm{t}$ as shown in Fig 8a gave the slope of $\frac{K 1}{2.303}$ and intercept of $\log _{10}$ qe. Table 3 showed the pseudo-first order constant values for biosorption of phosphate on ALB, CALB and TALB. A low $\mathrm{R}^{2}$ value (not close to unity) indicates that the model does not sufficiently describe the kinetic data. Disparity between Qe $(\mathrm{mg} / \mathrm{g})$ calculated and Qe $(\mathrm{mg} / \mathrm{g})$ experimental further suggest that this model does not sufficiently describe the data. According to pseudo-second order model assumptions, 'the rate limiting step may be chemisorption which involve valence forces brought about by sharing or exchange of electrons between sorbent material and sorbate (Aryal, 2011). Moreover, this model is also based on the 'sorption equilibrium capacity'. The values of Pseudo-second order plots (Fig 8b) are shown in Table 3. The $\mathrm{PO}_{4}{ }^{3-}$ adsorption on ALB gave $\mathrm{R}^{2}$ value of 0.945 and Qe experimental $(5.601 \mathrm{mg} / \mathrm{g})$ was found to be very close to the Qe calculated $(4.902 \mathrm{mg} / \mathrm{g})$, this suggest that biosorption process is best described by pseudo-second order kinetic model, similar results were also reported by $(\mathrm{Li}$ et al., 2013; Rathod et al., 2014; Song et al., 2011). Phosphate adsorption on CALB and TALB gave $\mathrm{R}^{2}$ value of 0.789 and 0.559 respectively, moreover differences between their Qe experimental and Qe calculated are negligible as shown in Table 2. One of the most used kinetic model for describing chemisorptions is Elovich model, it was originally developed to describe the kinetics of heterogeneous chemisorptions. Table 2 shows the constant values obtained when the kinetic data were fitted into Elovich model. Elovich plot was also represented in Fig8c.

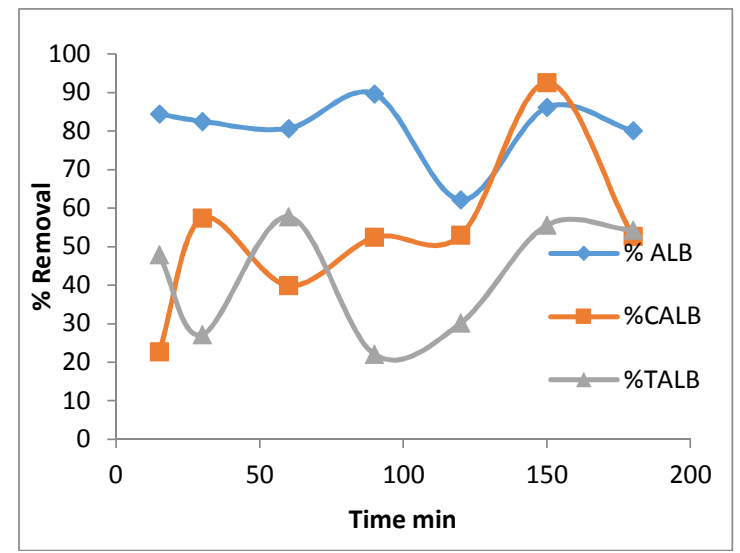

Fig 7: Effect of contact time on the biosorption of $\mathrm{PO}_{4}{ }^{3-}$ on Albizia lebbeck (ALB, CALB and TALB) pods powder.

Biosorption Mechanisms: The biosorption capacity was more pronounced with ALB biosorbent, this is majorly due to greater contribution of surface sorption and thickness of the biosorbent boundary layer as indicated by a large intercept value $\mathrm{C}$, in the intraparticle diffusion model as shown in Table 3 . Furthermore, the surface morphology of ALB as shown in Fig 1(a) indicate a large pore size compared to those of CALB and TALB. This could aid occlusion of phosphate ions onto the large pores thereby increasing biosorption capacity of the biosorbent. 
Table 1- Parameters of Biosorption Isotherm models for $\mathrm{PO}_{4}{ }^{3-}$ adsorbed by the three bisosorbent

\begin{tabular}{|c|c|c|c|c|c|c|c|c|c|}
\hline \multirow[t]{2}{*}{ Biosorbent } & \multicolumn{3}{|c|}{ Langmuir } & \multicolumn{3}{|c|}{ Freundlich } & \multicolumn{3}{|c|}{ Temkin } \\
\hline & $\mathrm{q}_{\max }$ & $\mathrm{k}_{\mathrm{L}}$ & $r^{2}$ & $\mathrm{n}$ & $\mathrm{K}_{\mathrm{F}}$ & $r^{2}$ & $\mathrm{~K}_{\mathrm{T}}$ & $\mathrm{b}_{\mathrm{T}}$ & $r^{2}$ \\
\hline ALB & 6.849 & 0.011 & 0.287 & 1.155 & 0.103 & 0.422 & 0.137 & 1.445 & 0.354 \\
\hline CALB & -0.152 & -0.002 & 0.958 & 0.188 & $3.68 \mathrm{E}-09$ & 0.802 & 0.033 & 0.395 & 0.535 \\
\hline TALB & -0.018 & -0.016 & 0.977 & 0.145 & $7.49 \mathrm{E}-13$ & 0.919 & 0.029 & 0.637 & 0.502 \\
\hline
\end{tabular}

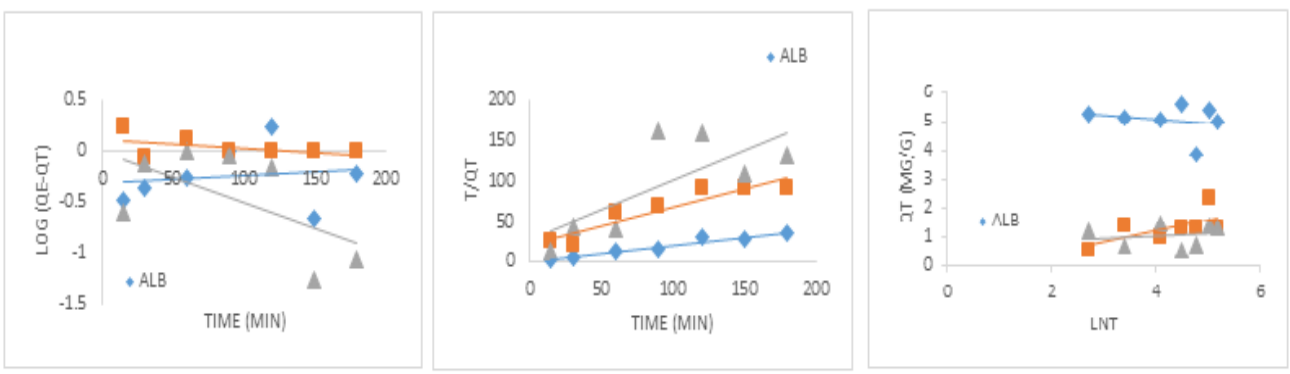

Fig. 8 - Adsorption kinetics of phosphates adsorption onto biosorbents: (a) pseudo-first-order, (b) pseudo-second-order, and (c) Elovich.

\begin{tabular}{|c|c|c|c|c|}
\hline \multirow{2}{*}{$\begin{array}{l}\text { Kinetic } \\
\text { Model }\end{array}$} & \multirow{2}{*}{ Parameters } & \multicolumn{3}{|l|}{ Values } \\
\hline & & ALB & CALB & TALB \\
\hline Pseudo $1^{\text {st }}$ & qe $(\mathrm{mg} / \mathrm{g})$ & 0.482 & 1.321 & 1.012 \\
\hline \multirow[t]{2}{*}{ Order } & $\mathrm{K} 1(1 / \mathrm{min})$ & 0 & 0 & 0.012 \\
\hline & $\mathrm{R}^{2}$ & 0.022 & 0.260 & 0.368 \\
\hline Pseudo $2^{\text {nd }}$ & Qe $(\mathrm{mg} / \mathrm{g})$ & 4.902 & 1.797 & 1.340 \\
\hline \multirow[t]{2}{*}{ order } & K2 (g/mgmin) & 0.771 & 0.0219 & 0.0217 \\
\hline & $\mathrm{R}^{2}$ & 0.945 & 0.789 & 0.559 \\
\hline \multirow[t]{3}{*}{ Elovich } & $\alpha$ & $-1.54 \mathrm{E}^{-18}$ & 0.18 & $6.2 \mathrm{E} 4$ \\
\hline & $\beta$ & -6.897 & 2.646 & 17.241 \\
\hline & $\mathrm{R}^{2}$ & 0.056 & 0.422 & 0.019 \\
\hline
\end{tabular}

Table 3: Intra-particle diffusion model for $\mathrm{PO}_{4}{ }^{3-}$

\begin{tabular}{llll}
\hline & \multicolumn{3}{c}{$\mathrm{PO}_{4}{ }^{3-}$} \\
\hline Parameters & $\mathrm{ALB}$ & $\mathrm{CALB}$ & $\mathrm{TALB}$ \\
\cline { 2 - 4 } $\mathrm{K}_{\mathrm{d}}(\mathrm{g} / \mathrm{mg} / \mathrm{min})$ & -0.035 & 0.095 & 0.022 \\
$\mathrm{C}(\mathrm{mg} / \mathrm{g})$ & 5.374 & 0.464 & 0.848 \\
$\mathrm{R}^{2}$ & 0.051 & 0.402 & 0.044 \\
\hline
\end{tabular}

Conclusion: In this study, the results show that the removal of phosphate was not enhanced by either citric acid or tartaric acid modification as shown by the 'maximum biosorption capacity' $\mathrm{Q}_{\max }$ of $6.849 \mathrm{mg} / \mathrm{g}$ by ALB. The binding of Phosphate on the three biosorbents is $\mathrm{pH}$ dependent and the optimum binding of phosphate on the three biosorbents occurred at acidic $\mathrm{pH}$ values. The equilibrium time to reach optimum sorption for ALB, CALB, and TALB are 90, 150 and $60 \mathrm{~min}$. The biosorption capacity of the three biosorbent also increases as the phosphate ion concentration increases with an equilibrium concentration of $50 \mathrm{mg} / \mathrm{L}$ for ALB. The outcome of this study suggests that albizia lebbeck can be utilized as a green, low-cost effective biosorbent and can compete very well with other biomass used for the sorption of phosphate from wastewater without chemical modification.

\section{REFERENCES}

Adediran, GO; Tella, AC; Mohammed, HA. (2007). Adsorption of $\mathrm{Pb}, \mathrm{Cd}, \mathrm{Zn}, \mathrm{Cu}$ and $\mathrm{Hg}$ ions on formaldehyde and pyridine modified bean husks. Journal of Applied Sciences and Environmental Management, 11(2).

Aharoni, C; Sideman, S; Hoffer, E. (1979) . Adsorption of Phosphate Ions by Collodion-Coated Alumina. Journal of Chemical Tech. Biotechnol., 29, 404-412.

Ahmed, MJ; Theydan, SK. (2013). Adsorption of pchlorophenol onto microporous activated carbon from Albizia lebbeck seed pods by one-step microwave 
assisted activation. Journal of Analytical and Applied Pyrolysis, 100, 253-260.

Akbal, F. (2005). Adsorption of basic dyes from aqueous solution onto pumice powder. Journal of colloid and interface science, 286(2), 455-458.

Anirudhan TS, B. F. N. (2006). Phosphate Removal from Wastewaters Using a Weak Anion Exchanger Prepared from a Lignocellulosic Residue, 40(8), 2740-2745.

Anthony, F; Godfrey, K. (2014). Simultaneous adsorption of $\mathrm{Ni}$ ( II ) and Mn ( II ) ions from aqueous solution unto a Nigerian kaolinite clay. Integrative Medicine Research, 3(2), 129-141.

Apha, A. (1998). Wpcf. Standard methods for the examination of water and wastewater, 20.

Aryal, M. (2011). Colloids and Surfaces A : Physicochemical and Engineering Aspects Equilibrium , kinetics and thermodynamic studies on phosphate biosorption from aqueous solutions by $\mathrm{Fe}$ ( III ) -treated Staphylococus xylosus biomass: Common ion effect. Colloids and Surfaces A: Physicochemical and Engineering Aspects, 387(1-3), 43-49.

Biswas, BK; Inoue, K; Ghimire, K. N; Harada, H; Ohto, K; Kawakita, H. (2008). Removal and recovery of phosphorus from water by means of adsorption onto orange waste gel loaded with zirconium. Bioresource Technology, 99(18), 8685-8690.

Bhargava, DS; Sheldarkar, SB. (1993). Use of TNSAC in phosphate adsorption studies and relationships. Effects of adsorption operating variables and related relationships. Water Research, 27(2), 313-324.

Carvalho, WS; Martins, DF; Gomes, FR; Leite, IR; Gustavo da Silva, L; Ruggiero, R; Richter, EM. (2011). Phosphate adsorption on chemically modified sugarcane bagasse fibres. Biomass and Bioenergy, 35(9), 3913-3919.

Chien, SH; Clayton, WR. (1955). Application of Elovich Equation to the Kinetics of Phosphate Release and Sorption in Soils 1, 1-4.

Das, J; Patra, BS; Baliarsingh, N; Parida, KM. (2006). Adsorption of phosphate by layered double hydroxides in aqueous solutions. Applied Clay Science, 32, 252 260.

Eberhardt, TL; Min, S. (2008). Biosorbents prepared from wood particles treated with anionic polymer and iron salt : E V ect of particle size on phosphate adsorption, 99, 626-630.

Eberhardt, TL; Min, S; Han, JS. (2006). Phosphate removal by refined aspen wood fiber treated with carboxymethyl cellulose and ferrous chloride, 97, 2371-2376.
El-sikaily, A; Nemr, A; El Khaled, A; Abdelwehab, O. (2007). Alga Ulva lactuca and its activated carbon.

Fernandez N, EC. (1995). The use of seed pods from Albizia lebbek....pdf.

Freundlich, H.M. F. (1906). Over the adsorption in solution. J. Phys. Chem, 57(385), e470.

Hale, SE; Alling, V; Martinsen, V; Mulder, J; Breedveld, GD; Cornelissen, G. (2013). The sorption and desorption of phosphate-P, ammonium-N and nitrate-N in cacao shell and corn cob biochars. Chemosphere, 91(11), 1612-1619.

Han, R; Wang, Y; Yu, W; Zou, W; Shi, J; Liu, H. (2007). Biosorption of methylene blue from aqueous solution by rice husk in a fixed-bed column, 141, 713-718.

Herut, B. (2002). Adsorption - Desorption of Phosphate on Airborne Dust and Riverborne Particulates in East Mediterranean Seawater, 3519-3524.

Karageorgiou, K; Paschalis, M; Anastassakis, GN.(2007). Removal of phosphate species from solution by adsorption onto calcite used as natural adsorbent, 139, 447-452.

Kumar, DH; Harinath, Y; Seshaiah, K; Reddy, AVR. (2010). Biosorption of $\mathrm{Pb}$ ( II ) from aqueous solutions using chemically modified Moringa oleifera tree leaves. Chemical Engineering Journal, 162(2), 626-634.

Langmuir, I. (1916). Adsorption of gases by solids. J. Am. Chem. Soc, 38(10), 2267.

Li, G; Gao, S; Zhang, G; Zhang, X. (2013). Enhanced adsorption of phosphate from aqueous solution by nanostructured iron ( III ) -copper ( II ) binary oxides. Chemical Engineering Journal, (Iii).

Low, MJD., (1960). Kinetics of chemisorption of gases on solids. Chemical Reviews, 60(3):267-312

Marshall, WE; Chatters, AZ; Wartelle, LH; Mcaloon, A. (2001). Optimization and estimated production cost of a citric acid-modified soybean hull ion exchanger, 14 , 191-199.

Marshall, WE; Wartelle, LH; Boler, DE; Johns, MM; Toles, CA. (1999). Enhanced metal adsorption by soybean hulls modi ${ }^{\circledR}$ ed with citric acid, 69 (July 1998), 263268.

Mezenner, NY; Bensmaili, A. (2009). Kinetics and thermodynamic study of phosphate adsorption on iron hydroxide-eggshell waste. Chemical Engineering Journal, 147, 87-96. https://doi.org/10.1016/j.cej.2008.06.024 
Neufeld, RD; Thodos, G. (1969). Removal of orthophosphates from aqueous solutions with activated alumina. Environ. Sci. Technol. 3, 661-667.

Özacar, M. (2003). Adsorption of phosphate from aqueous solution onto alunite. Chemosphere, 51(4), 321-327.

Park, D., Yun, YS., and Park, JM. 2010. The past, present, and future trends of biosorption. Biotechnology and Bioprocess Engineering, 15(1), 86-102. http://doi.org/10.1007/s12257-009-0199-4

Patil, PK; Patil, N; Vijay, M. (2012). Adsorption of Copper $\left(\mathrm{Cu}^{2+}\right)$ and $\mathrm{Zinc}\left(\mathrm{Zn}^{2+}\right)$ metal Ion from Waste Water by Using Soybean Hulls and Sugarcane Bagasse as Adsorbent, 1(September), 13-23.

Prochaska, CA; Zouboulis, AI. (2006). Removal of phosphates by pilot vertical-flow constructed wetlands using a mixture of sand and dolomite as substrate, 26, 293-303.

Rathod, M; Mody, K; Basha, S. (2014). Efficient removal of phosphate from aqueous solutions by red seaweed, Kappaphycus alverezii. Journal of Cleaner Production, 84(1), 484-493.

Raju, CA; Kumari, RS; Satya, CV; Rao, PJ; Bai, MT. (2012). Biosorption performance of Albezia lebbeck pods powder for the removal of lead: Application of statistical method, 2(3), 1297-1305.

Rhoton, FE; Bigham, JM. (2005). Phosphate Adsorption by Ferrihydrite-Amended Soils, 896(May 2004), 890-896.

Rodrigues, LA; Lúcia, M; Pinto, C. (2010). Thermodynamic and kinetic investigations of phosphate adsorption onto hydrous niobium oxide prepared by homogeneous solution method. DES, 263(1-3), 29-35.

Santana, W; Ferreira, D; Rosa, F; Gustavo, L; Ruggiero, R;
Mathias, E. (2011). Phosphate adsorption on chemically modified sugarcane bagasse fibres, 5, 1-7.

Song, X; Pan, Y; Wu, Q; Cheng, Z; Ma, W. (2011). Phosphate removal from aqueous solutions by adsorption using ferric sludge. DES, 280(1-3), 384390.

Uddin, MT; Islam, MS; Abedin, MZ. (2007). Adsorption Of Phenol From Aqueous Solution By Water Hyacinth Ash, 2(2), 11-17.

Ugurlu, A; Salman, B. (1998). Phosphorus removal by fly ash. Environment international, 24(8), 911-918.

Xiong, JB; Mahmood, Q. (2010). Adsorptive removal of phosphate from aqueous media by peat. DES, 259(1-3), 59-64.

Xu, X; Gao, B; Tan, X; Yue, Q; Zhong, Q; Li, Q. (2011). Characteristics of amine-crosslinked wheat straw and its adsorption mechanisms for phosphate and chromium ( VI ) removal from aqueous solution. Carbohydrate Polymers, 84(3), 1054-1060.

Yao, B; Xi, B; Hu, C; Huo, S; Su, J; Liu, H. (2011). A model and experimental study of phosphate uptake kinetics in algae: Considering surface adsorption and P-stress. Journal of Environmental Sciences, 23(2), 189-198.

Yeoman, S; Stephenson, T; Lester, JN; Perry, R. (1988). The removal of phosphorus during wastewater treatment: a review. Environ. Pollut. 49, 183-233.

Zhang, M; Gao, B; Yao, Y; Inyang, M. (2013). Chemosphere Phosphate removal ability of biochar / MgAl-LDH ultra-fine composites prepared by liquidphase deposition. Chemosphere. 